\title{
Comparison on the Use of Smartphone Application between International and Korean Pregnant Women
}

\author{
Hyeon Jihye and Syed Nitas Iftekhar
}

\begin{abstract}
Antenatal parent education(APE) is the key to solve numerous contemporary issues using education such as lessening brain development gap and reducing maternal and infantile mortality. Many researchers have examined existing APE on and off-line which have shown merits as well as limitations. Many of them urged research on alternatives to compensate the limitations, and the potential of education using ICTs such as Smartphone has been highlighted more recently. This study aims to analyze the current APE using Smartphone application comparing international users and Korean users with content analysis to conceptualize Smartphone efficiency for APE. The finding of content analysis was that parents need informing and supporting functions the most. Monitoring and shaping functions were regarded useful among users in terms of personalized APE. This result was accorded to both international and Korean users.
\end{abstract}

Index Terms-Parent education, antenatal parent education, Smartphone application, South Korea.

\section{INTRODUCTION}

As development of human beings can be measured by scientific tools nowadays, more and more convincing findings and theories have shed light on the significance of maternal environment since fertilization. These scientific findings have gradually caught attention of not only scientists but also education stakeholders and economists due to the magnificent effect of early period on the rest of life [1], [2]. The first and most influential figure on early life development is a mother who provides 10-month living environment directly since the very beginning, as well as, stays closely with young babies forming most of cognitive development from their nurturing environment [3]. In regard with this, new research and policy consensus has emerged in the developed world recently emphasizing parent education on account of the importance of early childhood development (ECD), cognitive development, maternal health, and antenatal care and education [4].

\section{LITERATURE REVIEW}

\section{A. Global Contexts}

The importance of early childhood development (ECD) has been given importance increasingly on national and

Manuscript received August 15, 2014; revised November 28, 2014.

Hyeon Jihye is with the Institute of International and Comparative Education, Beijing Normal University and UNESCO Beijing, China (e-mail: sophiehyeon@gmail.com).

Syed Nitas Iftekhar was with Beijing Normal University, China. He is now with Indian Institute of Corporate Affairs (IICA), Ministry of Corporate Affairs, Government of India, India (e-mail: nitas711@gmail.com). international level regarding the relationship between brain and cognitive development. Mostly developed nations have immense effort on ECD to strengthen human resources from the very beginning of one's life. The United States, for example, set 10 years from 1990 as 'decade of the brain' urging active research on brain-based education [5]. Following the research, conferences on ECD were held by White House such as 'The White House Conference on Early Childhood Development and Learning' in 1997 with early childhood educators and medical experts. As follow-up, 'The White House Summit on Early Childhood Cognitive Development' was hosted by Mrs. Bush, the former First lady, along with U.S. Secretary of Education and U.S. Secretary of Health and Human Services in 2001 [6]. One of the conclusions from these conferences was nurturing environment which parents provide directly and strongly affects creativity and brain development of babies [7]. President Barack Obama also has given priority to early children cognitive development with various policies to support this concept [8].

Japan also declared 'century of the brain' for the $21 \mathrm{st}$ Century putting all efforts on brain development [9]. The Centre for Educational Research and Innovation (CERI) of The Organization for Economic Co-operation and Development (OECD) in collaboration with some nations such as the U.S., Japan and the U.K. has conducted research projects on brain-based education, holding conferences and publishing research results [10]. More and more leaders and experts are ready to invest in ECD as human resources are seemingly regarded as the most crucial in knowledge economy. Accordingly, the role of parents who directly have an effect on ECD, is regarded as one of important factors in education and society.

\section{B. Korean Contexts}

South Korea has also conducted research on antenatal parent education in various ranges. Since many parents have already noticed the significance of prenatal care, there have been many ways to get APE for their babies; Off-line hospital checkups, health centers, newspapers, media, books, community centers, department stores, APE in forests, music concert for APE and on-line web-based educational programmes and even Smartphone [11]. Researchers have focused on the fact that internet can be a useful tool for parents to get information due to the merits which online education has, such as no restriction of time and place, fathers' participation, easy and effective educational tools with audio-visual aids, and cyber community to share information [12], [13].

On the other hand, there are evident shortcomings of the internet. Kim [12] argued that online parent educations hast 
not met the needs of parents who want privatized and professional parent education considering different family structures $^{1}$ and each baby's different development. That is to say, online parent education has no difference with other kinds of off-line parent educational methods which haven't dealt with individuals' different needs. Online parent education needs more practical education to give parents to solve the problem in the actual settings in real life. The strategy to keep parents' motivation to learn is seemingly lacking in online parent education as well [14]. Furthermore, health related information available to parents on the internet can be misleading and occasionally, utterly wrong [15]. One of the most exhaustive studies of the quality of health-related information available on the internet [15] comprised of 79 separate studies, which in turn consisted of analyses on 5941 web sites and 1329 web pages. The conclusion was $70 \%$ of samples had quality problems.

\section{Why Smartphone?}

The use of mobile devices in health care, also interchangeable with the term 'mHealth' [16], has increasingly gained attention among researchers because of its unlimited potential [17], [18]. Recently, Smartphone penetration rate on average is $44.6 \%$ in 47 countries, and this number has been on the rise [19].

Mobile phone is one of the leading mediums of information and communication technologies (ICT) as there are more users in economically undeveloped and developing countries than in developed countries [20]. mHealth can be used in developing countries to fill the health system gap which helps to reach the Millennium Development Goals [21]. The different functions of Smartphones such as calling, messaging, camera, recording and applications can be used for more various purposes regarding health care. A promising use of mHealth is data collection, both in developed countries and in developing countries [22]-[24].

The rate of using educational applications via Smartphone also has been going up constantly [25]. A research conducted in Korea showed that 99 percent participants were willing to use an application if it is useful to them [11]. This research concluded Smartphone applications for pregnant women will be an effective educational tool compared to other existing mediators even though frequency or scope of using it would be varied according to the user's age. Frequently mentioned challenges of research on APE using Smartphone are methodological issues and lack of strong evidence for the use of mHealth [26], [27]. Accordingly, Educational use of Smartphones in the real world has to be studied closely to seek advanced ways of antenatal parent education using ICTs.

\section{Why South Korea?}

In South Korea, more than 84 percent of population use internet, and Korean citizens spend around 5 hours on the internet per day. Smartphone penetration is 73 percent of the total population, and 94percent of them use their Smartphone to search for local information or to research products. South Korea's penetration rate of Smartphone ranked number one in the world in 2012 [28]. This environment has let Korean

${ }^{1}$ Such as families which have working moms, single-parent or divorced families and extended family etc. people to get used to this mobile technology and internet, which led to the creation of one of the leading Smartphone brands, Samsung Galaxy. Korea is therefore an appropriate country to research on this topic with the setting where Smartphone penetration rate is high enough comparing to overall international penetration rate. This study compared the use of Smartphone application between international and Korean pregnant women since some results can be peculiar to only Korean settings if only South Korea is looked into..

\section{E. Research Questions}

- What kind of applications and which functions pregnant women mostly use?

- What are the limitations which pregnant women face while using applications?

- What are the similarities and differences on application use between international users and Korean users?

\section{F. Limitations}

Despite the merits of APE using Smartphone, it is too early to implement in developing countries due to lack of resources and perception. According to We Are Social Singapore [28], there are around 2.5 billion global internet users today, about $35 \%$ of the world's population. The report divided the world into 12 regions, which consist of 5 regions that cannot reach the world average rate of internet users; Central America, Central Asia, Southeast Asia, Africa, South Asia. Almost 81percent of North America's population and 78percent of Western Europe have got penetrated by the internet, but only 18 percent of people residing in Africa and 12 percent in South Asia can get access to the internet. The internet is also distributed according to the existing economic ranking in the world. This is problematic since regions like Africa and South Asia which have low penetration rate are actually places where APE using Smartphone is needed due to its poor APE environment. Therefore, it seems that administrating the findings of this paper in less developed countries is not feasible at this moment, but constant endeavors to disseminate the quality APE using ICTs in the future are strongly required.

\section{CONCEPTUAL FRAMEWORK}

The following framework of Rotheram-Borus et al. [29] for mHealth APE using phones is adopted for this study.

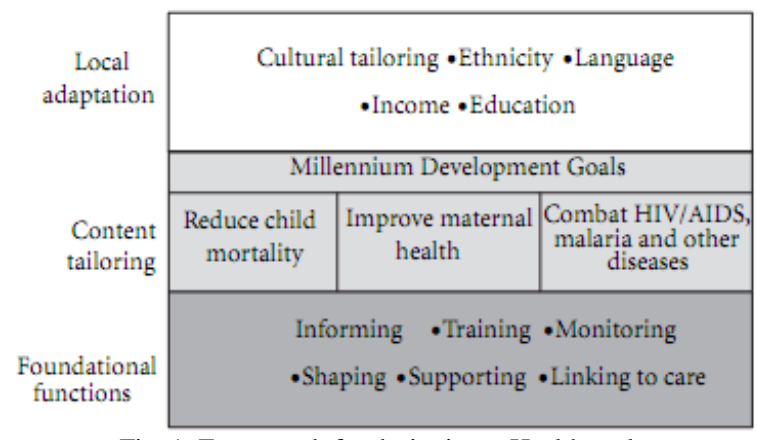

Fig. 1. Framework for designing mHealth tools

1) informing about health risks, healthy behaviors, and available resources;

2) training new behaviors by providing text messages, calls, pictures, or even videos that model the desired behaviors; 
3) monitoring behavior in real time, including unobtrusive and automatic monitoring to reduce the burden of self-monitoring;

4) shaping healthy behaviors through monitoring, feedback, prompts and reminders, encouragement, and rewards provided in real time;

5) supporting development and maintenance of healthy behavioral routines by linking to peers, friends, family, or healthcare workers for social support and instrumental support services;

6) linking to healthcare or results from diagnostics tests.

\section{RESEARCH DESIGN}

\section{A. Methodological Theory}

Phenomenology theory was used for this paper since the real experiences are crucial to look into the usage of Smartphone applications. The aim is to achieve real experience rather than second-hand one so that an actual APE program using Smartphone applications can be feasible in the real life. Based on this theory, the researchers of this paper tried to suspend any prejudgments about that reality and conduct participant-centered content analysis.

\section{B. Data Collection}

For content analysis of Smartphone applications, Android market 'Google play' was used to collect data due to its dominance in Korea. In the third quarter of 2013, Android's share of the global Smartphone shipment market was $81.3 \%$ [30]. The proportion of android phone is $78 \%$ in Korea in $2012 .^{2}$

The key words used for research were 'pregnant', 'fetus', 'fetal education', 'antenatal education', and 'antenatal parent education' in Korean and English respectively. Gathering data from applications was conducted in May, 2014. The filtering criteria for Korean applications and international applications were different in terms of the number of comments which users have left due to different demographic size.

For Korean applications, filtering criteria was; written in Korean, over 4.0 stars for grading, and over 800 users' comments for reliability free from marketing strategies by application providers. There were only two key words which gave reliable results. Those keywords gave 6 reliable applications of 373 in total. 'Pregnant' keyword had 250, and most of them were about pregnancy information or menstruation calendar. For 'fetal education', there were 123 applications regarding music and fairy tales for fetus. Even though keywords were typed in Korean, there were some applications written in another languages such as Chinese, Arabic and Russian.

The filtering criteria for international applications were also three; written in English, over 4.0 stars for grading, over 5000 users' comments. 6 reliable applications of 418 in total were chosen to be researched. 'Pregnant' keyword had 250 which is the same number of the same keyword in Korean. Some applications had functions for exercise like yoga, and

\footnotetext{
${ }^{2}$ http://www.koreainformationsociety.com/2012/06/smartphone-usagen-korea-new-snapshot.html
}

some apps seemed to show ultrasound imaging, but users didn't prefer to download it due to lack of proper function. There were another interesting functions such as pregnancy test based on symptoms, contraction timer, guide for sex during pregnancy, tips only for dad, pet pregnancy and diet plan during pregnancy. For 'fetus', there were 96 applications, but there was only one application which met the screening criteria. There were 48 from 'fetal education' which help mothers feel fetus like heartbeat sound, 5 from 'antenatal education', and 19 applications from 'antenatal parent education'.

\section{Findings}

TABLE I: SMARTPHONE APPLICATION ANALYSIS

\begin{tabular}{|c|c|c|c|c|c|c|c|c|c|}
\hline & & \multirow[b]{2}{*}{ Grading } & \multirow[b]{2}{*}{ Users } & \multicolumn{6}{|c|}{ Functions } \\
\hline & & & & $\begin{array}{l}\stackrel{\infty}{\Xi} \\
\text { 咅 } \\
\text { 号 }\end{array}$ & 营 & $\begin{array}{l}\text { 号 } \\
\text { 总 } \\
\text { 竞 }\end{array}$ & 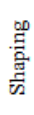 & 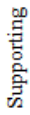 & $\begin{array}{l}\stackrel{\infty}{\Xi} \\
\text { 咅 }\end{array}$ \\
\hline \multirow{7}{*}{ 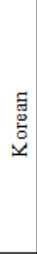 } & My baby's music box & 4.2 & 2845 & $\checkmark$ & & & $\sqrt{ }$ & & \\
\hline & Music collection for fetus & 4.3 & 800 & v & & & & & \\
\hline & WomanL og Calender & 4.6 & 84694 & & & $\checkmark$ & v & & \\
\hline & Mom talk & 4 & 1186 & & & & $\checkmark$ & $\checkmark$ & \\
\hline & My Pregnancy Today(Korean) & 4.6 & 118183 & $\checkmark$ & $\checkmark$ & $\checkmark$ & $\sqrt{ }$ & $\sqrt{ }$ & \\
\hline & Mom's diary & 4.8 & 3406 & & & $\checkmark$ & $\checkmark$ & $\checkmark$ & \\
\hline & Average & 4.4166667 & 35185.667 & 3 & 1 & 3 & 5 & 3 & 0 \\
\hline \multirow{7}{*}{ 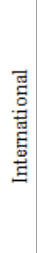 } & My Pregnancy Today & 4.6 & 120851 & $\checkmark$ & $\checkmark$ & $\checkmark$ & v & $\sqrt{ }$ & \\
\hline & BabyBump Pregnancy Free & 4.6 & 29329 & $\sqrt{ }$ & $\checkmark$ & $\checkmark$ & $\sqrt{ }$ & $\checkmark$ & \\
\hline & Happy Pregnancy Ticker & 4.5 & 7416 & $\sqrt{ }$ & $\checkmark$ & $\checkmark$ & $\sqrt{ }$ & $\checkmark$ & $\checkmark$ \\
\hline & Im Ex pecting-Pregnancy & 4.6 & 37409 & $\checkmark$ & & $\checkmark$ & $\sqrt{ }$ & $\sqrt{ }$ & \\
\hline & I'm Pregnant & 4.4 & 7141 & $\sqrt{ }$ & $\sqrt{ }$ & & $\checkmark$ & & $\checkmark$ \\
\hline & Pregnancy Tracker & 4 & 5473 & & & $\checkmark$ & $\checkmark$ & & \\
\hline & Arerage & 4.45 & 34603.167 & 5 & 4 & 5 & 6 & 4 & 2 \\
\hline
\end{tabular}

While around 34,603 international users left comments on the most popular 6 applications, almost 35,186 Korean users also did even though its demographic size is relatively smaller than other countries. This shows how much Korean pregnant women have had huge interests in APE using Smartphone applications comparing to international average. The average number of functions contained in the 6 applications, Korean ones have 3 in average but international applications have 4.33 functions which are almost twice than Korean. Another notable finding is almost all applications have shaping function except one Korean application. And 5 of international applications have informing and monitoring functions which 3 Korean applications have.

\section{DISCUSSION}

\section{A. Korean Applications}

6 reliable applications searched from Korean version were My baby's music box, Music collection for fetus, WomanLog Calender, Mom talk, My pregnancy Today (Korean version), Mom's diary. 'Fetal education' key word gave us almost only music applications, mainly consisting of classic music for educational effects. 'Pregnant' key word searched 6 similar applications about menstruation calculate calendar. Functions of each application were almost the same, so most popular one WomanLog Calender was analyzed. Two most popular applications, My Pregnancy Today and Mom's diary contain 
5 functions out of 6 framed by Rotheram-Borus et al. [30]. Out of 6 in total, there were 3 applications having informing function, 1 for training, 3 for monitoring, 5 for shaping, 3 for supporting. Interesting thing is there was no application to have linking function in these applications.

The most popular application My Pregnancy Today has informing, training, monitoring, shaping, supporting functions, but mostly focusing on informing. Parents were satisfied with this function as they can see daily or weekly development of fetus. This is a Korean translated version of English-written application, but some users complained that it doesn't have some useful functions which English version has. Analysis for Korean applications didn't show that the more functions an application has, the more users prefer to use it.

What users prefer in the second popular application Mom's diary was a free service to send a book if a parent keeps a diary for consecutive 100 days. This can be not only encouragement for parents to keep recording their pregnancy and nurturing, but also exchange information among parents searching other parents' diaries to see what they went through in the same situation before. There were even some comments to ask to make an application for only this diary function. This much, the level of parents' satisfaction on this function was very high. Besides, Mom talk and Mom's diary offer events such as providing chances to use pregnancy- or nurturing-related goods for free and to purchase those goods in groups with lower price than original. This shows that applications for APE give parents opportunities for free or low-priced goods regarding pregnancy and nurturing as well as advertise products to parents. Some users put negative comments as well; non user-friendly interface, frequent technical errors, pop-up adds, frauds who pretend to sell products.

\section{B. International Applications}

According to users' comments, most of parents were satisfied with the pictures to see what is going on their baby inside. First-time moms or busy working moms seem to prefer to use applications because of schedule management and regularly delivered pregnancy information. They use this kind of applications with husband or other families to share fetal development information. Some users prefer to the function comparing the fetus size to fruits, but others don't because some fruits are not familiar with them and the size of fruits can be varied in different regions. Negative comments were generally about lack of diversity and personalized information. Most of applications provided white baby images, not the Asian or black, and they focused on only one-baby pregnancy, not twins. There were some problems on different time zones as well as pop-up adds, but comments about technical problems were the most among complaints. Some users commented that a separated application for fathers or life partners would be helpful as well. Others left some complaints on the layout or design of the applications and the content construction.

Based on users' comments, the most important functions which users likely cared were informing and supporting as Korean users did. But these functions can be found online as well, so monitoring and shaping functions are crucial for users to keep using Smartphone applications for personalized APE which other offline and online educational methods are not capable of providing effectively. And the table 1 doesn't show that the more functions an application has, the more users prefer to use it as Korean applications did. For example, Happy pregnancy ticker has all six functions in it, but there were some comments about accuracy of information. This shows the number of functions do not that much matter. $M y$ pregnancy today has the highest number of users as there were no negative comments on inaccurate information. Therefore, informing can be considered as a very important function for users to decide usefulness of an application. Also supporting function to communicate with other peer parents was considered as an important fact for users to determine usefulness. Linking function can be useful in the future if it is actively used by hospitals and pregnant women who can't visit hospitals frequently or regularly due to jobs or economic situation.

\section{CONCLUSION}

Even though pregnancy period has already been regarded crucially in terms of lifelong health and cognitive development, there have been few strong educational policy to guarantee every parent get proper Antenatal Parent Education regardless of their own status and background. Accordingly, more and more educational researchers and experts have kept trying to come up with better methods for APE during pregnancy to apply it effectively and broadly. Researchers have not only examined existing APE on and off-line but also have urged alternatives to compensate the limitations. In accordance with this, the potential of education using ICT such as Smartphone has been given more emphasis recently. This is why Smartphone applications in use for APE should be studied closely. As South Korea is one of leading countries in terms of ICT, it is worth to compare Korean usage of Smartphone applications for APE to international one.

Among six functions of mHealth framed by Rotheram-Borus et al. (2012), informing, monitoring, shaping and supporting functions were preferred the most in Smartphone applications for APE among users in Korea. Among these four important functions, monitoring and shaping are peculiar for Smartphone to meet parents' needs for personalized APE care which other offline and online methods can't provide effectively. There were only six referable applications with the basic key words which users would use when they want to download APE applications from Google play. Most available applications for pregnancy - such as managing nutrition intake, recommending the type of exercise and recording the history of exercise, introducing reliable scientific studies for parents' behaviors to help develop fetal development and nurturing environment should be easily searchable with basic key words such as 'pregnant' or 'antenatal parent education' so that parents can get easily access to those.

Even though parents seem to rely on peer parents' feedback in both Korean and international applications, there is no reliable device to scrutinize whether the information peer parents provided is correct. To ensure reliability of information, macro organizations such as government are required to set up a trustable tool to help parents get right 
sources for APE. Based on analysis, 'linking' function which connects parents with medical centers is expected to be active to help parents who can't go to hospital freely due to time or regional restriction. This function can also be activated by macro organizations' efforts and investment, not only by application developers.

An unified platform of APE using various methods integrating on and offline should be prepared to provide personalized and professional APE to meet every pregnant woman's different needs efficiently. This is because parents want personalized information to fit each parent's condition and situation, not general information. Accordingly, APE using Smartphone as a medium is encouraged more as ICTs have been considered significantly when it comes to different individual needs and different situation.

From the comparative analysis between Korean and international applications in use, our suggestions for application are the followings; based on users' opinions, it would be good to have "grouping function" with people who the user nominates. In this way, this group is able to get the same information as the user does every day or every week. Furthermore, there are no applications for the illiterate, so it would be good to have a "reading function" with picture or video for those. In regard with this, applications should be designed in an easy way for everyone. Furthermore, these kinds of applications should be linked with on and offline APE as well in order to maximize the effect of APE.

Quantitative research using questionnaire has dominated in this field so far. Therefore, more qualitative studies on impression of parents or practitioners engaged in APE are recommended for the future research to fit the needs of those involved in. This paper conducted qualitative research to fill this gap, but bigger sample size of interview is also needed to recheck the findings of this paper.

\section{REFERENCES}

[1] J. Li et al., "Late gestational maternal serum cortisol is inversely associated with fetal brain growth," Neuroscience \& Biobehavioral Reviews, vol. 36, no. 3, 2012.

[2] M. D. Giudice, "Fetal programming by maternal stress: Insights from a conflict perspective," Psychoneuroendocrinology, vol. 37, no. 10, 2012.

[3] D. J. P. Barker, "In utero programming of chronic disease," Clinical Science, vol. 95, no. 2, 1998, pp. 115-128.

[4] T. Hyun, E. Y. Lim, N. Kang, and K. N. Kim, "Prenatal breastfeeding education and infant feeding practices in public health centers and baby-friendly hospitals," Korean Journal of Community Nutrition, vol. 6 , no. 4 , 2001, pp. 678-685.

[5] M. F. Bear, B. W. Connors, and M. A. Paradiso, Neuroscience Exploring the Brain, USA: Lippincott Williams \& Wilkins, 2001

[6] The White House. (May 2, 2014). The White House Summit on Early Childhood Cognitive Development. [Online]. Available: http://georgewbush-whitehouse.archives.gov/firstlady/initiatives/educ ation/earlychildhood.html

[7] ABCDE. (May 2, 2014). The White House Conference on Early Childhood Development and Learning. [Online]. Available: http://clinton3.nara.gov/WH/New/ECDC/

[8] The White House. (May 2, 2014). Early Childhood Learning. [Online]. Available: http://www.whitehouse.gov/issues/education/early-childhood

[9] J. Y. Cho, "The principle and direction of creative education based on brain science," Student's Life Study, Seoul National University of Education, 27, 2011, pp. 115-141.

[10] OECD, Understanding the Brain: Towards a New Learning Science, Paris: OECD Publishing. 2002

[11] S. B. Kim, J. W. Kim, M. H. Kim, Y. S. Cho, S. N. Kim, H. S. Lim, and S. K. Kim, "A study on consumer's needs for development of diet guide application for pregnant women," Korean Journal of Community Nutrition, vol.18, no.6, pp. 588-598, 2013.

[12] Y. Kim, "Reconsidering for the efficient operation of web-based parent education," Korean Journal of Family Welfare, vol. 8 no. 1, pp. 17-33, 2003.

[13] H. J. Seo and Y. S. Seo, "Predictor of participation and achievement in web-based parent education program," 2002.

[14] G. Eysenbach, J. Powell, O. Kuss, and E. R. Sa, "Empirical studies assessing the quality of health information for consumers on the world wide web: A systematic review," Jama, vol. 287, no. 20, pp. 2691-2700, 2002.

[15] C. P. Waegemann, "MHealth: The next generation of telemedicine," Telemed JE Health, vol. 16, no. 1, pp. 23-25, 2010.

[16] W. A. Kaplan, "Can the ubiquitous power of mobile phones be used to improve health outcomes in developing countries," Global Health, vol. 2, no. 9, pp. 399-404, 2006.

[17] Z. W. Chen, L. Z. Fang, L. Y. Chen, and H. L. Dai, "Comparison of an SMS text messaging and phone reminder to improve attendance at a health promotion center: A randomized controlled trial," Journal of Zhejiang University Science B, vol. 9, no. 1, pp. 34-38, 2008.

[18] Our Mobile Planet. (2013). [Online]. Available: http://www.thinkwithgoogle.com/mobileplanet/en/graph/?wave=2012 \&age $=$ all\&gender $=$ all\&chart_type $=\&$ active $=$ wave

[19] ITU-D. (2011). The World in 2011 ICT Facts and Figures. [Online] Available:

http://www.itu.int/ITU-D/ict/facts/2011/material/ICTFactsFigures20 11.pdf

[20] J. G. Kahn, J. S. Yang, and J. S. Kahn, "Mobile' health needs and opportunities in developing countries," Health Affairs, vol. 29, no. 2, pp. 252-258, 2010.

[21] H. M. Whitford, P. T. Donnan et al., "Evaluating the reliability, validity, acceptability, and practicality of SMS text messaging as a tool to collect research data: Results from the Feeding Your Baby project," Journal of the American Medical Informatics Association, vol. 19, no. 5, pp. 744-749, 2012.

[22] M. Moller, J. Attermann, G. Myklebust, and N. Wedderkopp, "Injury risk in Danish youth and senior elite handball using a new SMS text messages approach," British Journal of Sports Medicine, vol. 46, no. 7, pp. 531-537, 2012.

[23] S. M. Schembre and J. Yuen, "Project TwEATs: A feasibility study testing the use of automated text messaging to monitor appetite ratings in a free-living population," Appetite, vol. 56, no. 2, pp. 465-468, 2011.

[24] J. Kaewkungwal, P. Singhasivanon, A. Khamsiriwatchara, S. Sawang, P. Meankaew, and A. Wechsart, "Application of smart phone in 'Better Border Healthcare Program': A module for mother and child care," BMC Med Inform Decis Mak, 2010.

[25] Y. M. Seo and Y. J. Lee, "Analysis of educational Smartphone applications and mobile educational services trends," Journal of Korean Association of Computer Education, vol. 14, no. 2, pp. 9-13, 2010.

[26] M. Tomlinson, M. J. Rotheram-Borus, L. Swartz, and A. C. Tsai, "Scaling up mHealth: Where is the evidence?" PLoS Medicine, vol. 10, no. 2, p. e1001382, 2013.

[27] V. Vodopivec-Jamsek, T. de Jongh, I. Gurol-Urganci, R. Atun, and J. Car, "Mobile phone messaging for preventive health care," Cochrane Database Syst Rev, Dec. 2012.

[28] We Are Social Singapore. (March 22, 2014). Social, Digital \& Mobile around the World. [Online]. Available: http://www.slideshare.net/wearesocialsg/social-digital-mobile-around -the-world-january-2014

[29] M. J. Rotheram-Borus, M. Tomlinson, D. Swendeman, A. Lee, and E Jones, "Standardized functions for Smartphone applications: Examples from maternal and child health," International Journal of Telemedicine and Applications, vol. 2012, 2012.

[30] I. Lunden, "Android, led by samsung, Continues to storm the Smartphone market, pushing a global 70\% market share," TechCrunch., AOL Inc., 2013.

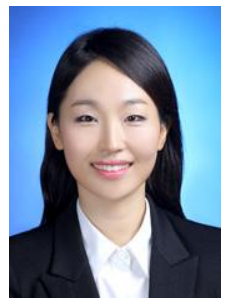

Hyeon Jihye was born in Seoul, Republic of Korea, and she got a bachelors' degree of English literature and language in Hanyang University in Seoul, Republic of Korea in 2007. Since she got awarded Korean Government Scholarship and Chinese Government Scholarship in 2013, she has been studying for a master's of international comparative education in Beijing Normal University in Beijing, China. Her major field of study is parent education, especially 
antenatal parent education for pregnancy and nurturing using ICTs. Her paper regarding this field won the grand prize in a research contest held by UN Global Compact in 2014; The title of the paper is Emerging Models for Technologically-enabled CSR: Antenatal Parent Education to Reduce Maternal and Infantile Mortality in Ghana.

She worked in the field of academic curriculum and educational planning \& management in Republic of Korea since 2004. Currently she has worked in UNESCO Beijing Cluster Office as a research associate. The UNESCO projects she has been involved are ICT in education in Democratic People's Republic of Korea, CCE (Climate Change Education) in Mongolia, TVET (Technical and Vocational Education and Training) for young migrant workers in China.

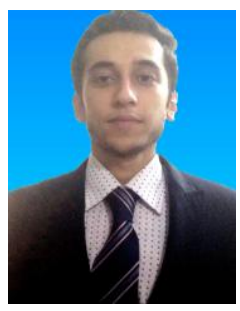

Syed Nitas Iftekhar was born and brought up in New Delhi, India after which he went to China for post graduate studies in the field of Education. He completed his M.A. degree in comparative education and policy, Beijing Normal University, Beijing, China in 2014.

Since 2007, he has worked extensively at the grass-roots level in NGOs in India focusing on education, literacy and women empowerment. He has conducted research on various topics, as a research associate for UNESCO INRULED and UNESCO, Beijing Head Office. Currently, he is working at Indian Institute of Corporate Affairs (IICA), Ministry of Corporate Affairs, Government of India, New Delhi on Corporate Social Responsibility related activities.

Mr. Syed is also a member for Comparative International Education Society and Bulgarian Comparative Education Society. He had been awarded the Chinese Government FulBright Scholarship for his Masters Degree and Outstanding International Student award from Beijing Normal University. He has contributed to some important international publications such as China Ten Year EFA Report (UNICEF-UNESCO) and Skills Development for Rural Transformation (INRULED). 